\title{
Personalized radiotherapy for invasive breast cancer in 2017
}

\author{
National S3 guidelines and DEGRO and AGO recommendations
}

\author{
Frederik Wenz ${ }^{1}$ (D) $\cdot$ Wilfried Budach ${ }^{2}$
}

Received: 17 May 2017 / Accepted: 19 May 2017 / Published online: 19 June 2017

(c) Springer-Verlag Berlin Heidelberg 2017

Radiotherapy in the curative setting for breast cancer has evolved over the past 15 years, from a one size fits all approach to a personalized, risk-adapted treatment within a multidisciplinary environment, taking more and more patient factors, the biology of the tumor, and the extent of disease in the lymph nodes into account. Before the year 2000 , the picture was straightforward, with no radiotherapy following mastectomy (postmastectomy radiotherapy, PMRT), and whole breast radiotherapy (WBRT) with $50 \mathrm{~Gy}$ over 5 weeks after breast-conserving surgery in all patients. The picture is more complex today (see Fig. 1).

\section{Postmastectomy radiotherapy}

The Danish and British Columbia trials [1-3] identified preand postmenopausal patients with locally advanced tumors (T3-4Nx or $\mathrm{TxN}+$ ) for whom an overall survival benefit was achieved by postmastectomy radiotherapy (PMRT) of $50 \mathrm{~Gy}$. The initial consensus was that patients with four and more positive nodes benefitted the most in terms of over-

Members of the S3 guideline committee for breast cancer of the German Cancer Society

Members of the Working Group Breast Cancer (AG Mamma) of the German Society for Radiation Oncology (DEGRO)

Radiation oncology representatives of the Working Group

Oncology Breast (AGO Mamma), German Cancer Society

$\triangle$ Frederik Wenz

frederik.wenz@umm.de

1 Klinik für Strahlentherapie und Radioonkologie, Universitätsmedizin Mannheim, Universität Heidelberg, Theodor-Kutzer Ufer 1-3, 68167 Mannheim, Germany

2 Klinik für Strahlentherapie und Radioonkologie, Heinrich Heine Universität, Moorenstr 5, 40225 Düsseldorf, Germany all survival; however, a recent analysis by the Early Breast Cancer Trialists' Collaborative Group (EBCTCG) [4] underlined that patients with one to three positive nodes also showed a consistent benefit, particularly when chemotherapy was given. This benefit is substantial in high-risk patients (G3, triple negative, lymph vascular invasion, Her2 positive, or age $<40$ years) [5]. One should keep in mind that all patients included in the EBCTCG analysis received PMRT to the chest wall and regional nodal irradiation (RNI; medial supraclavicular and mostly mammary internal). On the other hand, there was a lack of consistent benefit for all T3N0 patients. Meta-analyses have identified subgroups of the T3N0 category with risk factors, e.g., large tumor, young age, high grading, lymph vessel invasion, and triple negative, which may still show a benefit based on the individual risk assessment, particularly when two or more risk factors are positive $[6,7]$.

Concerning the situation after neoadjuvant chemotherapy, there is still a paucity of data regarding the indication for PMRT. Therefore, the initial clinical staging before neoadjuvant chemotherapy is used until ongoing prospective studies have reported results (e. g., NSABP B 51).

In summary, PMRT is currently recommended in patients with $\mathrm{T} 4$ or $\mathrm{N}+$ disease, or following $\mathrm{R}+$ resection. PMRT can be avoided following R0 mastectomy in T1-2N0 patients and in T3N0 patients without risk factors. Typically, PMRT should include the chest wall and the regional nodal areas [7].

\section{Radiotherapy and breast-conserving surgery}

Radiotherapy is an integral part of the breast-conserving therapy approach. If at all, no radiotherapy following breast conserving surgery (BCS) may be an option for patients 

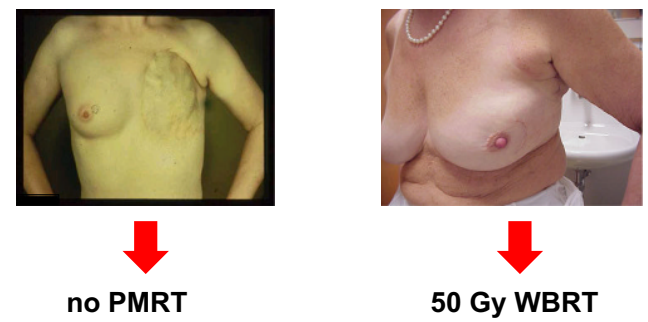

b

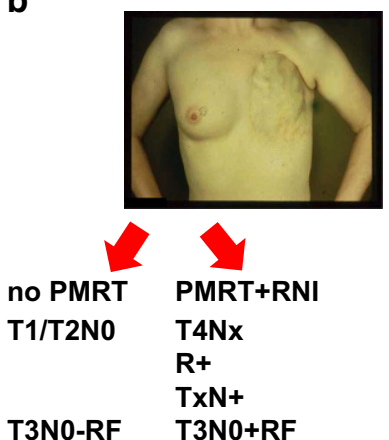

(risk factors L1, G3, (>T2), triple neg, $\geq 2 \mathrm{RF}$...)

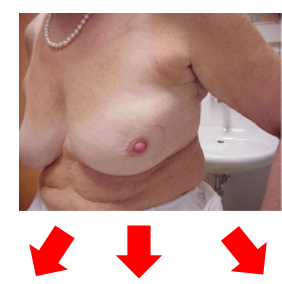

APBI WBRT WBRT+boost IORT hypofx int boost brachy IORT boost EBRT brachy boost $+/-$ RNI

Fig. 1 Adjuvant radiotherapy for breast cancer; a before 2000, b in 2017. PMRT postmastectomy radiotherapy, WBRT whole breast radiotherapy, $R N I$ regional nodal irradiation, $A P B I$ accelerated partial breast irradiation, IORT intraoperative radiation therapy, brachy brachytherapy, EBRT external beam radiotherapy, Int integrated, $R F$ risk factors

whose life expectancy is shorter than 10 years, with hormone receptor-positive T1N0 tumors without Her2neu overexpression. Patients have to be counselled that even with rigorous antihormonal therapy, there is a considerably increased risk for local recurrence (CALBG, BASO2, PRIME II trials: 4-6\% local recurrence without radiotherapy after 5 years for patients above 70/65/65 years of age with receptor-positive T1N0 tumors; non-grade III; for a summary see $[8,9])$.

Based on long-term results from three randomized studies, (accelerated) partial breast irradiation ((A)PBI) using intraoperative radiotherapy or postoperative multicatheter brachytherapy or external beam radiotherapy is an option for postmenopausal patients with low-risk tumors (T1N0, R0 resection, hormone receptor positive, non-lobular histology). Participation in a clinical study is recommended for patients between 50 and 70 years of age [10-12].

Fractionated WBRT is the standard of care for the overwhelming majority of patients following BCS. Hypofractionated WBRT, i. e., the application of single doses larger than 2 Gy up to reduced total doses, e.g., 15-16 fractions of $2.66 \mathrm{~Gy}$, has been shown in large randomized trials with sufficient follow-up to be at least as effective in terms of local tumor control as conventionally fractionated radiotherapy and results in significantly less acute and late effects [13-15]. Consequently, hypofractionated radiotherapy is the preferred radiation schedule in patients who do not need radiotherapy of regional lymph nodes. In younger and high-risk patients, a sequential boost of 10-16 Gy to the tumor bed is recommended, although the improvement in local control is modest and there was no overall survival benefit in long-term follow-up [16, 17].

Based on the PMRT data, two recent randomized trials (MA20, EORTC), and a Danish cohort study [18-20], the indication for RNI was expanded following BCS [21-23]. Depending on the number of positive nodes $(>3,1-3,0$ but high risk), the strength of the recommendation to include the supraclavicular/medial axillary region decreases in AGO (++, +, +/-) and in S3 (have to/should/can). In most of the cases where RNI is indicated, irradiation of the internal mammary nodes should be considered (for a detailed analysis see [23]). Typically, conventional fractionation is used when RNI is given following BCS. Based on the AMOROS trial, it is obvious that RNI yields lower rates of side effects following sentinel node biopsy compared to radical axillary dissection [24].

\section{Conclusion}

This short overview summarizes the current developments in risk-adapted radiotherapy for breast cancer. One has to keep in mind that the different guideline committees come to slightly different conclusions depending on the composition of their membership and the process of literature collection and interpretation [25-27].

Conflict of interest F. Wenz and W. Budach declare that they have no competing interests.

\section{References}

1. Overgaard M, Hansen PS, Overgaard J, Rose C, Andersson M, Bach F, Kjaer M, Gadeberg CC, Mouridsen HT, Jensen MB, Zedeler K (1997) Postoperative radiotherapy in high-risk premenopausal women with breast cancer who receive adjuvant chemotherapy. Danish Breast Cancer Cooperative Group 82b Trial. N Engl J Med 337(14):949-955

2. Overgaard M, Jensen MB, Overgaard J, Hansen PS, Rose C, Andersson M, Kamby C, Kjaer M, Gadeberg CC, Rasmussen BB, Blichert-Toft M, Mouridsen HT (1999) Postoperative radiotherapy in high-risk postmenopausal breast-cancer patients given adjuvant tamoxifen: Danish Breast Cancer Cooperative Group DBCG 82c randomised trial. Lancet 353(9165):1641-1648

3. Ragaz J, Jackson SM, Le N, Plenderleith IH, Spinelli JJ, Basco VE, Wilson KS, Knowling MA, Coppin CM, Paradis M, Coldman AJ, Olivotto IA (1997) Adjuvant radiotherapy and chemotherapy in node-positive premenopausal women with breast cancer. N Engl J Med 337(14):956-962

4. Early Breast Cancer Trialists' Collaborative Group (2014) Effect of radiotherapy after mastectomy and axillary surgery on 10-year recurrence and 20-year breast cancer mortality: meta-analysis of 
individual patient data for 8135 women in 22 randomised trials. Lancet 383(9935):2127-2135

5. Li Y, Moran MS, Huo Q, Yang Q, Haffty BG (2013) Post-mastectomy radiotherapy for breast cancer patients with $\mathrm{t} 1 \mathrm{-t} 2$ and 1-3 positive lymph nodes: a meta-analysis. PLOS ONE 8(12):e81765

6. Recht A, Comen EA, Fine RE, Fleming GF, Hardenbergh PH, Ho AY, Hudis CA, Hwang ES, Kirshner JJ, Morrow M, Salerno KE, Sledge GW Jr, Solin LJ, Spears PA, Whelan TJ, Somerfield MR, Edge SB (2016) Postmastectomy radiotherapy: An American Society of Clinical Oncology, American Society for Radiation Oncology, and Society of Surgical Oncology Focused Guideline Update. J Clin Oncol 34(36):4431-4442

7. Wenz F, Sperk E, Budach W et al (2014) DEGRO practical guidelines for radiotherapy of breast cancer IV: radiotherapy following mastectomy for invasive breast cancer. Strahlenther Onkol 190(8):705-714

8. Matuschek C, Bölke E, Haussmann J, Mohrmann S, Nestle-Krämling C, Gerber PA, Corradini S, Orth K, Kammers K, Budach W (2017) The benefit of adjuvant radiotherapy after breast conserving surgery in older patients with low risk breast cancer - a metaanalysis of randomized trials. Radiat Oncol 12(1):60

9. Vaidya JS, Bulsara M, Wenz F, Joseph D, Saunders C, Massarut S, Flyger H, Eiermann W, Alvarado M, Esserman L, Falzon M, BrewGraves C, Potyka I, Tobias JS, Baum M, TARGIT trialists' group (2015) Pride, prejudice, or science: attitudes towards the results of the TARGIT-A trial of targeted Intraoperative radiation therapy for breast cancer. Int J Radiat Oncol Biol Phys 92:491-497

10. Strnad V, Ott OJ, Hildebrandt G, Kauer-Dorner D, Knauerhase H, Major T, Lyczek J, Guinot JL, Dunst J, Gutierrez Miguelez C, Slampa P, Allgäuer M, Lössl K, Polat B, Kovács G, Fischedick AR, Wendt TG, Fietkau R, Hindemith M, Resch A, Kulik A, Arribas L, Niehoff P, Guedea F, Schlamann A, Pötter R, Gall C, Malzer M, Uter W, Polgár C, Groupe Européen de Curiethérapie of European Society for Radiotherapy and Oncology (GEC-ESTRO) (2016) 5-year results of accelerated partial breast irradiation using sole interstitial multicatheter brachytherapy versus whole-breast irradiation with boost after breast-conserving surgery for low-risk invasive and in-situ carcinoma of the female breast: a randomised, phase 3, non-inferiority trial. Lancet 387(10015):229-238

11. Vaidya JS, Wenz F, Bulsara M, Tobias JS, Joseph DJ, Keshtgar M, Flyger HL, Massarut S, Alvarado M, Saunders C, Eiermann W, Metaxas M, Sperk E, Sütterlin M, Brown D, Esserman L, Roncadin M, Thompson A, Dewar JA, Holtveg HM, Pigorsch S, Falzon M, Harris E, Matthews A, Brew-Graves C, Potyka I, Corica T, Williams NR, Baum M, TARGIT trialists' group (2014) Riskadapted targeted intraoperative radiotherapy versus whole-breast radiotherapy for breast cancer: 5-year results for local control and overall survival from the TARGIT - A randomised trial. Lancet 383(9917):603-613

12. Livi L, Meattini I, Marrazzo L, Simontacchi G, Pallotta S, Saieva C, Paiar F, Scotti V, De Luca Cardillo C, Bastiani P, Orzalesi L, Casella D, Sanchez L, Nori J, Fambrini M, Bianchi S (2015) Accelerated partial breast irradiation using intensity-modulated radiotherapy versus whole breast irradiation: 5-year survival analysis of a phase 3 randomised controlled trial. Eur J Cancer 51(4):451-463

13. Whelan TJ, Pignol J-P, Levine MN et al (2010) Long-term results of hypofractionated radiation therapy for breast cancer. N Engl J Med 362(6):513-520

14. Haviland JS, Owen JR, Dewar JA et al (2013) The UK Standardisation of Breast Radiotherapy (START) trials of radiotherapy hy- pofractionation for treatment of early breast cancer: 10-year follow-up results of two randomised controlled trials. Lancet Oncol 14:1086-1094

15. Hickey BE, James ML, Lehman M, Hider PN, Jeffery M, Francis DP, See AM (2016) Fraction size in radiation therapy for breast conservation in early breast cancer. Cochrane Database Syst Rev 7:CD003860

16. Bartelink H, Maingon P, Poortmans P, Weltens C, Fourquet A, Jager J, Schinagl D, Oei B, Rodenhuis C, Horiot JC, Struikmans H, Van Limbergen E, Kirova Y, Elkhuizen P, Bongartz R, Miralbell R, Morgan D, Dubois JB, Remouchamps V, Mirimanoff RO, Collette S, Collette L, European Organisation for Research and Treatment of Cancer Radiation Oncology and Breast Cancer Groups. (2015) Whole-breast irradiation with or without a boost for patients treated with breast-conserving surgery for early breast cancer: 20-year follow-up of a randomised phase 3 trial. Lancet Oncol 16(1):47-56

17. Sedlmayer F, Sautter-Bihl ML, Budach W et al (2013) DEGRO practical guidelines: radiotherapy of breast cancer I: radiotherapy following breast conserving therapy for invasive breast cancer. Strahlenther Onkol 189(10):825-833

18. Whelan TJ, Olivotto IA, Parulekar WR et al (2015) Regional nodal irradiation in early-stage breast cancer. $\mathrm{N}$ Engl $\mathrm{J}$ Med 373(4):307-316

19. Poortmans PM, Collette S, Kirkove C et al (2015) Internal mammary and medial supraclavicular irradiation in breast cancer. N Engl J Med 373(4):317-327

20. Thorsen LB, Offersen BV, Dano H et al (2016) DBCG-IMN: a population-based cohort study on the effect of internal mammary node irradiation in early node-positive breast cancer. J Clin Oncol 34(4):314-320

21. Budach W, Kammers K, Boelke E, Matuschek C (2013) Adjuvant radiotherapy of regional lymph nodes in breast cancer - a metaanalysis of randomized trials. Radiat Oncol 8(1):267

22. Budach W, Bolke E, Kammers K et al (2015) Adjuvant radiation therapy of regional lymph nodes in breast cancer - a meta-analysis of randomized trials- an update. Radiat Oncol 10:258

23. Sautter-Bihl ML, Sedlmayer F, Budach W, Dunst J, Feyer P, Fietkau R, Fussl C, Haase W, Harms W, Piroth MD, Souchon R, Wenz F, Sauer R (2014) DEGRO practical guidelines: radiotherapy of breast cancer III-radiotherapy of the lymphatic pathways. Strahlenther Onkol 190(4):342-351

24. Donker M, van Tienhoven G, Straver ME et al (2014) Radiotherapy or surgery of the axilla after a positive sentinel node in breast cancer (EORTC 10981-22023 AMAROS): a randomised, multicentre, open-label, phase 3 non-inferiority trial. Lancet Oncol 15(12):1303-1310

25. AGO (2017) Empfehlungen gynäkologische Onkologie Kommission Mamma. http://www.ago-online.de/de/infothek-fuer-aerzte/ leitlinienempfehlungen/mamma/. Accessed May 11, 2017

26. AWMF (2012) Leitlinien-Detailansicht Mammakarzinom der Frau; Diagnostik, Therapie und Nachsorge (Version 2012). http://www. awmf.org/leitlinien/detail/11/032-045OL.html. Accessed May 11, 2017

27. Krug D, Baumann R, Budach W, Dunst J, Feyer P, Fietkau R, Haase W, Harms W, Piroth MD, Sautter-Bihl ML, Sedlmayer F, Souchon R, Wenz F, Sauer R, Breast cancer expert panel of the German Society of Radiation Oncology (DEGRO) (2017) Current controversies in radiotherapy for breast cancer. Radiat Oncol 12(1):25 